\title{
Moving from collaboration to critical dialogue in action in education
}

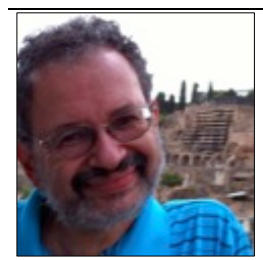

Eugene Matusov

University of Delaware, USA

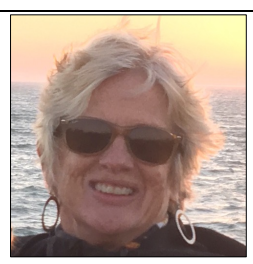

Lucinda Pease-Alvarez

University of California Santa Cruz, USA

\begin{abstract}
The purpose of this article is to examine and conceptualize our pedagogical and organizational experiences and understandings of how undergraduates and instructors participating in the UC-Links Project from Fall 1996 to Spring 1997 learned together through their engagements in undergraduate courses and afterschool activities with predominantly Mexican-descent children at a local community center. We had started our project privileging collaboration and collaborative guidance as the way to approach our collective engagements; however, the events in the project pushed us to reconsider our practice. It took us 25 years to completely understand that what we have come to call "critical dialoguing in action" is how we now conceive of innovative organizational and pedagogical practice, which stands in contrast to the pedagogical and organizational notion of collaboration. We describe the efforts and struggles participants, including ourselves, encountered developing, implementing, and communicating about innovative teaching approaches and practices that we originally thought aimed to promote meaningful and collaborative learning. We call particular attention to dilemmas participants faced dialoguing about the dynamic teaching/learning processes that emerged in our project. These experiences prompted us to characterize our vision for participants' involvement in the project as "critical dialoguing in action," which contributed to our ongoing analysis and understanding of emerging dilemmas in our work.
\end{abstract}

Eugene Matusov is a Professor of Education at the University of Delaware. He studied developmental psychology with Soviet researchers working in the Vygotskian paradigm and worked as a schoolteacher before immigrating to the United States. He uses sociocultural and Bakhtinian dialogic approaches to education. His recent books are: Matusov, E. (2017). Nikolai N. Konstantinov's authorial math pedagogy for people with wings, Matusov, E. \& Brobst, J. (2013). Radical experiment in dialogic pedagogy in higher education and its Centauric failure: Chronotopic analysis, and Matusov, E. (2009). Journey into dialogic pedagogy.

Lucinda Pease-Alvarez is professor emerita of education at the University of California, Santa Cruz, where she also directed the teacher education program. Her research focuses on the meaning making practices of multilingual children and the development of pedagogical perspectives that build on the resources that these children and their families bring to schools and classrooms. She is also engaged in research examining how teachers of immigrant students are responding to and negotiating educational policy. Her scholarship in teacher education is focused on investigating how prospective teachers' experiences with language minority children and their families outside of school informs their pedagogies. She is a co-author of Pushing Boundaries: Language and Culture in a Mexicano Community (Cambridge University Press) and Teachers of English Learners Negotiating Authoritarian Policies (Springer) and co-editor of Learning, 


\section{Moving from collaboration to critical dialogue in action in education}

Eugene Matusov, Lucinda Pease-Alvarez

Teaching, and Community: Contributions of Situated and Participatory Approaches to Educational Innovation (Lawrence Erlbaum).

\section{Acknowledgement}

We thank all participants for their dedication and contributions to developing and realizing the UCLinks Project.

$\cos (0380$

\section{Introduction}

When we began the project that is the focus of this article, we conceived of learning/teaching as a collaborative endeavor involving multiple stakeholders. As educators, we believed in the notion of "collaborative guidance" developed by our colleague, Barbara Rogoff, together with her research group. According to Rogoff's conceptual framework, collaborative guidance involves examining and building on each other's ideas and actions in order to work toward a common goal or to solve some shared problem (Matusov, Bell, \& Rogoff, 2002; Rogoff, 2014, 2016; Rogoff, Matusov, \& White, 1996; Rogoff, Mejia-Arauz, \& Correa-Chávez, 2015). However, as we describe below, we became increasingly frustrated with the concept of collaboration as it proved to be constraining and inadequate, prioritizing agreements over disagreements, which, we felt were especially important when it came to negotiating the diversity of perspectives and goals held by stakeholders in a community-university partnership known as UCSC Links. Consequently, as we reflected on the events that we describe here, we embraced the challenges in our collective work, moving away from collaboration, away from shared goals, away from shared problems, and away from agreement and consensus as the engines of guidance and collective action, turning toward a Bakhtinian notion of dialogue (Bakhtin, 1999).

In describing the experiences and perspectives of those who have participated in the UC Links project between Fall 1996 and Spring 1997, we aim to share with the reader a meaningful educational event that represents an important departure from what we have experienced as university students and faculty and from the collaborative approach that we had endorsed. While several themes emerged through our involvement in the project, we feel that critical dialoguing in action stands out as a central feature of our work. Critical dialoguing in action involves participants considering alternative ideas and recursively testing them in dialogue and in practice. The qualification "in action" emphasizes that testing ideas involves their application in the participants' practice rather than just through discourse. That is to say, our engagement in this project is a story about learning what it means to critically dialogue with others, which was sometimes both very painful and very exciting. Participants often found their involvement in the project painful when, from their vantage point, their (and our) closely held and cherished beliefs were questioned, critiqued, or challenged. At the same time, many of them were excited and pleased as they discovered new commitments that they might like more than old ones and engaged in warm and caring relations with their collaborators on projects that mattered to all involved in them.

\section{Profile of the UCSC-Links Project}

Established in the Fall of 1996, the UC-Links Project was a multi-campus initiative that involved undergraduates and low-income K-12 students attending after school programs. According to project founders, UC administrators supported this initiative because they saw it as part of outreach efforts aimed at mitigating the effects of proposition 209, which eliminated the use of affirmative action as a means to equalize the educational and economic opportunities available to minority populations. The overall purpose of the UC-links Fifth Dimension system was to develop a "community-university pipeline" for low-income 


\section{Moving from collaboration to critical dialogue in action in education}

Eugene Matusov, Lucinda Pease-Alvarez

youth through the development of innovative research-driven education, based on informal learning assisted by university undergraduate students. The projects were comprised of afterschool programs for youth that were established as partnerships between community organizations and UC campuses.

At UCSC, undergraduates of diverse cultural backgrounds enrolled in a variety of UC Links courses in Education and Psychology that were linked to a practicum where they worked in an afterschool program twice a week for an hour-and-a-half with primarily Mexican-descent lower-income elementary school children. The program was affiliated with a community-based organization committed to violence prevention and community empowerment. The afterschool program ran four times a week during three University quarters. It provided opportunities for undergraduates and children to engage in a variety of activities, such as arts and crafts (e.g., movie making, clay sculpturing), reading, computer games, Internet exploration, homework, and outside activities (e.g., soccer and basketball games, hikes and walks, and excursions to nearby recreational spots). Generally, many undergraduates opted to continue their involvement in the UCLinks Project more than one quarter by enrolling in other UC-Links courses (e.g., continued enrollment ranged from a few students to over half of the class).

Many projects at other campuses adhered to and expanded upon the Fifth Dimension organizational structure developed by Michael Cole (2006). According to this structure, undergraduates worked with youngsters, many of whom come from low-income, minority communities, as they engaged in a range of computer-mediated activities, most of which were delineated via a set of task cards aligned according to the level of difficulty (e.g., beginner, expert). Tasks cards were organized in what was termed a maze, which specified the order in which tasks were to be completed. After the children solved all the problems set out in the task cards in a specific room of the maze, they were allowed to move to the next room. The undergraduate students were responsible for guiding children as they moved through the maze. The wizard, an anonymous entity within the Fifth Dimension, resolved conflicts and bestowed permissions and awards on specific children. Contact between children and the wizard occurred via email and other computer-mediated exchanges. Once children completed the activities specified in all of the task cards in the maze, they were deemed to be wizard assistants ${ }^{1}$.

UC Links sponsors anticipated that programs across the UC system would draw heavily on the Fifth Dimension structure. As we mentioned above, the UCSC-Links program was originally grounded in a commitment to developing a collaborative learning community. This commitment drove our decision not to adopt the features of other Fifth Dimension projects. We chose not to have a "wizard," "maze," or "task cards" as typical of other Fifth Dimension projects (Cole, 2006; Nicolopoulou \& Cole, 1993). Based on our observations of other Fifth Dimension sites, we worried that these structural features, imposed by adults, fostered a learning milieu in which adults were primarily responsible for monitoring and directing children's learning away from adult-child collaboration. Relying on an anonymous wizard as an authority figure seemed to deny children, undergraduates, and others the opportunity to engage in a collaborative learning community characterized by shared governance and interpersonal problem-solving. Moreover, given that two of the main emphases of our partner agency, the community center we worked with, were community building and violence prevention, we could not visualize how we could support these two emphases using an anonymous "wizard" to mediate conflict, especially when the children were expected to learn how to handle difficult conflicts that arose in the real-world settings outside of UC-Links where no wizards are available. Hence, children, children's families, undergraduates, staff, and instructors (including the authors of the article) worked hard to negotiate problems and dilemmas in ways that maximized our collective resources. This entailed developing a communal approach to negotiating a problem in which all participants

${ }_{1}^{1}$ Further details about the definition, description, and justification of Fifth Dimension organizational structures may be found at: http://etec.ctlt.ubc.ca/510wiki/The_Fifth_Dimension\#How the_Fifth_Dimension_Works. 


\section{Moving from collaboration to critical dialogue in action in education}

Eugene Matusov, Lucinda Pease-Alvarez

shared and critically examined the many sides of an issue or dilemma at hand. We drew upon our own emerging perspectives on teaching and learning with an emphasis on involving all participants in defining and shaping practices that matter to them.

Building on our interest in developing a program that emphasized mutuality in ownership and our respect for the participants' agency, our decision not to use a maze and task cards also emanated out of a concern that we could not predefine activities that children would find meaningful and engaging. In addition, opting not to use the "maze" related to leaders' concerns that the "maze" preemptively decided the trajectory of children's involvement in activities in ways that might create conflicts between the children, who might want to choose whatever activities they like, and the undergraduates, who might feel responsible for making sure that children complete activities in accordance with the way they were ordered in the maze (our thensuspicions were later supported by research of the 5th Dimension projects, see Nocon, 2005). We also could not envision how task cards could support and guide children as they participated in a given activity. The ordering of task cards from "simpler" to "more difficult" (predefined by the experts) did not seem like an adequate way to accommodate differences in children's learning, interests, and skills, and to provide guidance. We thought collaborative guidance and learning opportunities would more likely optimally occur when children engaged in activities on their own terms, and in negotiation with other participants, without potential obstacles of, for example, a script, curricular endpoints, goals, and procedures defined in advance by so-called experts.

Our perspective on this issue was confirmed when we observed children redefining the goals of activities to make them fit their level of skills and interests. For example, from the game designers' point of view, the educational computer game "Oregon Trail" involved planning, problem-solving, and decision making about how to survive as nineteenth-century American pioneers moving across the continent (Bigelow, 1996). However, for some children learning how to play the game, the goal of the game became being the first player to move through the stages of the game to reach the stage where hunting animals was allowed so that they could shoot as many animals as possible. For some other children, killing all of the travelers as soon as possible was the initial goal of the game. At first, undergraduate students working with the children felt that children who took these approaches to Oregon Trail were "off-task" or "cheating" when playing the game. However, according to students' later observations, children changed their goals as their playing skills and familiarity with the games progressed (see a similar observation of children's involvement with "Oregan Trail" in another afterschool program, Matusov \& Smith, 2011). In our view, task cards with prescribed procedures and goals attached to games like "Oregon Trail" would have contributed to unnecessary conflicts between undergraduates and children (Nocon, 2005). These conflicts would have possibly disrupted the students-children's relations, inhibited the children's playful activities, and limited the nature of the guidance undergraduates ultimately provided children (and vice versa).

The organization and flow of our courses distinguished our project from other Fifth Dimension programs. At UCSC, UC-Links courses were flexibly organized to help undergraduates become actively involved in designing a safe learning environment for the children and themselves and reflect on and analyze their experiences with the children in order to help them. Undergraduates were expected and encouraged to critique the existing classroom and practicum practices, raise concerns and issues, provide suggestions on how to make changes and address concerns, test their proposals in practice, and participate in decision making about program practices. When students and instructor disagreed about ways of implementing and changing pedagogical practices and defining problems, students' suggestions and definitions were not overruled by the instructor but rather considered and weighed against:

1. the possibility that the instructor's views might be wrong or problematic, 


\section{Moving from collaboration to critical dialogue in action in education}

Eugene Matusov, Lucinda Pease-Alvarez

2. the opportunities for critical reflective learning that might occur if students were able to implement their own plans, even if an instructor deemed them to be problematic or even wrong,

3. the wellbeing of all the participants as a result of the students' suggested actions,

4. the development of the students' authorial agency (i.e., we considered our students to be the authors of their own education), and

5. the support that students' actions required.

Opportunities for reflection and analysis were organized through a variety of venues that included in-class and online discussions, debriefings following practicum sessions, and group projects that involved students investigating some aspect of their work with children.

\section{From sociocultural transformation of participation to critical dialogue in action}

As we have mentioned, our work with children and undergraduates was originally guided by sociocultural and collaborative conceptual and pedagogical approaches that conceive of learning as participants' transformation of participation in community practices (Lave \& Wenger, 1991; Matusov, 1998; Rogoff, 1990). Pedagogical perspectives that draw upon sociocultural and collaborative views of learning emphasize participants' collaborative and voluntary involvement in meaningful activities of their own choosing. Through their collaborative interactions, participants consider and act on issues, inquiries, and/or tensions of concern to them as they work toward a shared goal. In this way, participants' actions converge to attain a SINGLE goal. Their engagement in activities is supported and transformed as they collaborate with other community members so that all participants play active and flexible roles in the learning process. As participants engage in shared endeavors of cultural, communal, and personal significance with others, they gradually come to take on new roles and responsibilities (Engeström, 1990; Rogoff, 1990). This perspective conceives of learning as meaning-making that leads to a collaborative agreement among participants who engage in shared endeavors (Rogoff et al., 1996).

A key feature of a collaborative approach that is also an important aspect of critical dialoguing is its horizontal organization. That is to say, participants' roles and relationships in the dialogue are not hierarchically structured. Participants, regardless of their ages and experiences, engage in predominantly horizontally-oriented interactions where they fluidly share roles and responsibilities in each other's learning. Using Bakhtin's philosophical framework of ontological dialogism, we tried to treat all the participants as having "consciousnesses with equal rights" (Bakhtin, 1999, p. 6).

Our current notion of "critical dialoguing in action" is influenced by the work of Matusov and Marjanovic-Shane who have introduced the notion of "critical ontological dialogue," which values and builds on disagreements, misunderstanding, and dissensus in the field of dialogic pedagogy (Marjanovic-Shane, 2016; Marjanovic-Shane, Meacham, Choi, Lopez, \& Matusov, 2019; Matusov, 2009, 2015a, 2015b, 2018; Matusov \& Marjanovic-Shane, 2012, 2015, 2019). Thus, in contrast to the notion of collaboration, critical dialoguing in action is not predicated on the idea that participants share or must come to share experiences, cultural practices, goals, or understandings. Further, unlike conventional approaches defining dialogue only as forms of linguistic expression (Bakhtin, 1986), critical dialogue in action involves testing diverse ideas in a dialogue, in which participants with differing, yet valuable experiences are engaged together verbally and nonverbally in dialogic moves of action and reflection. The goals of critical dialoguing in action go beyond the discovery of a "correct" answer or finding a collaborative resolution to a problem to encompass processes of transforming ownership-based engagements as participants jointly consider and 


\section{Moving from collaboration to critical dialogue in action in education}

Eugene Matusov, Lucinda Pease-Alvarez

enact or undertake their activity or interaction. Ownership-based engagement ${ }^{2}$ involves the legitimacy of all participants to define and redefine the goal of the activity and the nature of their discourse. Consequently, part of critical dialoguing entails not assuming or privileging specific cultural experiences, practices, goals, or understandings. All of these aspects are open to examination and transformation at any point in the process of addressing a topic, problem, or dilemma. Further, the notion of establishing a common ground or consensus is not a goal of critical dialoguing. When resolutions to a problem do emerge in critical dialoguing, they are often temporary and yield a new chain of problems and considerations that beg further critical dialogic reflection and action that test alternative ideas. Thus, from this critical dialogic perspective, education is viewed as a mainly deconstructive, rather than a constructive process (Marjanovic-Shane, 2016; Matusov \& Marjanovic-Shane, 2012, 2019). This perspective is contrasted with a sociocultural perspective that often views education as creative or closed socialization in an existing practice, which is a constructive process (Lave \& Wenger, 1991).

Hence, the dialogic process we describe here is characterized by a spiraling, meandering, and often unique trajectory rather than a universal linear from here to there, from process to product, from means to ends pathway. It means that participants reconsider a past concern from a different vantage point, thereby rendering a multifaceted and unpredictable spin on the way they come to participate in the project. For example, instructor and undergraduates considered the progress in their practice by comparing new and old problems, by pondering the consequences of their actions, and by reevaluating their priorities, goals, and values -- in other words, their new ways of being (Argyris \& Schön, 1978; Lave, 1992, April).

In the following sections, we focus on the events that have led us to introduce the notion of "critical dialoguing in action." These events led to important transformations in both the project and the participants' learning. We call attention to the significance and facets of these events by illustrating specific challenges participants encountered that disrupted their practice and even threatened their communal ecology (Matusov, 1999). These events were moments that helped us became intently aware of and critically reflective about differences in the actions, meanings, purposes, and perspectives among all participants engaged in UC-Links practices and community. Although we could not fully conceptualize these challenges and our new dialogic approaches to them when they occurred, we view these challenges as important crossroads or milestones for the project's continued wellbeing as they were moments of transformation.

\section{You can't order people to collaborate}

Having many students in the project, who actively subscribed to an adult-run educational philosophy, based on adults' unilateral decision-making, posed an interesting dilemma for us as we had tried to introduce a collaborative educational philosophy based on mutuality and shared responsibility for providing guidance, managing learning, and evaluating our practices (Rogoff et al., 1996). Basically, we wanted to mold all our students in our collaborative educational philosophy and our particular views on social justice. But we came to realize that we wanted to make them like us.

By adult-run, we mean a pedagogical perspective that is grounded in the notion that adults define and direct children's learning. In conventional school settings, this most often begins with adults identifying the gap between what students have already known and what they must know by testing children's ability to accomplish specific skills, with a focus on determining what children don't know (i.e., a "deficit model").

\footnotetext{
${ }^{2}$ Not any engagement is owned by the participant. For example, students' engagement in school activities are often driven by the external forces of a reward-punishment system, like grading, that are not owned by the student.
} 


\section{Moving from collaboration to critical dialogue in action in education}

Eugene Matusov, Lucinda Pease-Alvarez

These tests are used as the basis for deciding on what adults will do to guide or support children in learning those skills that they appeared not to have mastered.

When we began the project, we thought teaching and learning were always productive goaldirected activities of bringing our students to some desired outcome, but we struggled to define what this desired outcome should be for our students. Did we want to make all the students think like us, or should we leave them alone with their own beliefs, or should we all (students and professors) decide on some collaborative agreements? What about those students who wanted to try other educational philosophies how would we address their needs and provide them with appropriate guidance on how they should engage with children? We experienced a tension between the visionary aspect of our collaborative approach to teaching and our pluralistic pedagogical approach, emphasizing students' freedom to experiment, make mistakes, and even assume pedagogical ideas and values that are different from our own (Matusov \& Marjanovic-Shane, 2016).

Our dilemma was that, on the one hand, we could not wholeheartedly support some students pushing for creating an adult-run learning environment in the UC-Links Project. Essentially, those students seemed to want to bring conventional schooling to the afterschool program, apparently motivated by their conviction that many of the minority children were failing in their schools and, thus, needed extra adult guidance and practice. We did not believe in such an approach, saw a lot of problems with it, and could not use it and do it well (i.e., the visionary concern). We thought that many children had been failing in schools where an adult-run environment is common, and it did not make sense to us to repeat the same educational environment at UC-Links. On the other hand, we were aware that overruling and dismissing the students' concerns and requests for guidance within their adult-run teaching approach would be in itself a reconstruction of an adult-run approach by us (i.e., the pluralistic concern). We did not want to impose our view of a collaborative (and later critical dialogic) educational model on the students who did not see a need for it. We were stuck, as the following event illustrates.

During the first UC-Links class that Eugene (the course instructor and the first author of this article) and the two Teaching Assistants (TAs) taught, there was an intense discussion among the instructor, TAs, and undergraduate students about how to run the UC-Links program better. The class was split almost equally into two groups of students expressing two different approaches. The first group of students insisted that there was a need to test children's reading, writing, and math skills in order to diagnose and prescribe individualized guidance for these children as is often done in conventional schools (i.e., the "adult-run approach") (Rogoff et al., 1996). These students thought time playing games with children was not educational - they wanted to introduce school-like assignments to the children.

The second group of students did not support the idea of testing children suggesting that doing so would be a repetition of the same type of guidance that failed the children in the first place (namely in schools). These students also disagreed with the claim that the games did not have any educational value. They backed up their opinion by citing examples of children learning reading, math, and writing while playing games (i.e., probably reflecting a combination of the "collaborative" and "child-run" 3 approaches) (Rogoff et al., 1996).

However, examples of children's learning as they played games provided by the second group apparently did not convince the first group of students. They thought that these examples were merely

\footnotetext{
${ }^{3}$ In a "child-run" approach, a teacher leaves children to their own devices and provides minimum help when being asked. In a "collaborative approach" the responsibility for guidance and learning are flexibly distributed between the student and the teacher (Rogoff, et al., 1996). We wonder if the derogatory term "glorified babysitters" used by some of our students referred to the "child-run," hands-off, pedagogical approach (although it might also have referred to some other pedagogical approaches).
} 


\section{Moving from collaboration to critical dialogue in action in education}

Eugene Matusov, Lucinda Pease-Alvarez

"incidental learning" (i.e., learning that happens by an incident - random, unpredictable, unsystematic, contextual, and fragmented ${ }^{4}$ ) and instead argued for the establishment of a more structured learning environment at the UC-Links Program, where learning is targeted, predictable, systematic, universal, and holistic.

Eugene really liked the class discussion among the students because it demonstrated students' ownership of the program as well as their differing views and educational philosophies. However, he did not know what to do with this philosophical diversity - especially in terms of how to guide the students. On the one hand, he wanted to side with the second group of students because he agreed that the children and students learned a lot from playing games together. He also thought that learning through playing games was authentic because it was embedded in the activities that the children liked and selected. While children played games, they were interested, competent, active, successful, struggling, and willing learners. On the other hand, Eugene did not want to silence (or be perceived as silencing) the first group of students if they openly opposed the second group of students. Eugene also suspected that one of the reasons that the first group of students did not think that children learn from playing a variety of games was related to the difficulties that the students had guiding and supporting children as they played games. He had observed the first group of students interrupting the children's play with their scaffolding, quizzing, or, what can be called, schoolish guidance (Dorr-Bremme \& McDougall, 1999, April). Scaffolding involves simplifying tasks to be learned by children, managing children's motivation, challenges, and frustration, and developing procedural steps of guidance that predictably lead children to the curricular outcome preset by the adult (Rogoff, 1990; Wood, Bruner, \& Ross, 1976). In contrast, in order to support children as they played games, undergraduates needed to understand the children's dynamic and situated goals and needs (including needs for getting help) and appreciate and acknowledge the children's ideas. In addition, children and undergraduates had to enjoy being with one another (Matusov, Smith, Soslau, Marjanovic-Shane, \& von Duyke, 2016).

So, after some trepidation and soul searching, Eugene made the decision to prioritize students' ownership of the program and their own learning through active exploration of their philosophical disagreements. Thus, when students in the first group decided it would be good to test children to diagnose the children's educational deficits in order to decide what they should be taught, Eugene decided not to prevent them from doing so. However, he asked those students to report back to the class what transpired during those occasions when students tested or attempted to test children. He also suggested to the second group of students that they provided the class with more examples of occasions when children learned to read, write, or do math while playing games.

In the spirit of critical dialoguing, Eugene wanted the first group of students to first experience the process of testing children and then reflect on the consequences of their testing. In particular, he wanted the first group of students to compare the nature of their relationships with the children they tested with those of the other students who spent time playing games with children. There were uncertainties and risks involved with these suggestions, such as the possibility of creating a community of school-like test makers/takers; children losing interest in the program distrusting it, and deciding not to attend; and disciplinary problems along with adversarial relations that might emerge among the students and children.

\footnotetext{
${ }^{4} \mathrm{Cf}$. the notion of "incidental learning", "a subcategory of informal learning is defined by Watkin as a byproduct of some other activity such as task accomplishment interpersonal interaction, sensing the organizational culture trial-and-error experimentation or even formal learning. ... Incidental learning ... almost always take place although people are not always conscious of it" (Marsick \& Watkins, 1990, p. 12).
} 


\section{Moving from collaboration to critical dialogue in action in education}

Eugene Matusov, Lucinda Pease-Alvarez

A few days later, Saul ${ }^{5}$, a student from the first group, came to Eugene and one of the Teaching Assistants after class to ask for advice about how to test all children in reading, writing, and math. After trying out a test that he had developed on a few children, Saul asked the class instructor how to discipline and keep children on task when testing their academic skills for educational deficits because many of the children, whom he was testing, moved away from his testing activity and, thus, from him. Saul saw the solution to this problem as tighter control of the activities and eliminating "non-educational," "purely entertaining," games at the UCSC-Links Project. In fact, he wanted the instructor to enforce the use of only "educational" activities in the program so that children would learn academic skills and not be distracted from participating in his tests.

One of his math tests was on the recognition of geometric figures, using the Microsoft Paint software for Windows 95 . He asked young children at the community center to draw and label geometric figures (e.g., triangles, circles, squares) thinking that this test would prepare the children for learning the software as well as diagnosing their educational "handicaps" and "deficits." He was convinced that this was particularly important for minority children who often failed in schools. Saul thought that, unlike traditional paper and pencil tests, his computer tests were authentic because they were "hands-on" and "fun." However, he noticed that many children chose to play with the Microsoft Paint program instead of completing his test.

In discussion with Saul, Eugene tried to focus on revealing Saul's tacit assumptions about teaching/learning. He asked Saul why he needed to test the children if he could see how well they worked with geometric figures while drawing on the computer. Saul replied that he thought kids needed to label or distinguish geometric figures in isolation in order to work with these figures across different abstract contexts (like in school). Saul insisted that "objective testing" helps reveal children's "deficits" - i.e., the gaps between the children's performance and correct solutions, - which according to him was always the prerequisite for sensitive guidance (cf. the notion of "scaffolding" in Rogoff, 1990; Wood et al., 1976).

Saul and Eugene's conversation then shifted to a discussion of Microsoft Paint (i.e., what kind of activities could be done with children using this software). Sitting at the computer and playing with the program, Eugene and Saul concluded that Microsoft Paint was not a very good program for free drawing, but very useful for making collage pictures using preexisting geometric forms available in the program. Eugene suggested that Saul develop several attractive pictures (e.g., faces, houses) using the geometric forms available in Microsoft Paint, show the pictures to the children, and help them create their own collages. Saul was a bit skeptical about how creating collages with children would help him to diagnose "where the kids are in math." Eugene suggested that Saul could try this approach, compare it with his own approach, and then report his findings in class.

\footnotetext{
${ }^{5}$ A pseudonym.
} 


\section{Moving from collaboration to critical dialogue in action in education}

Eugene Matusov, Lucinda Pease-Alvarez

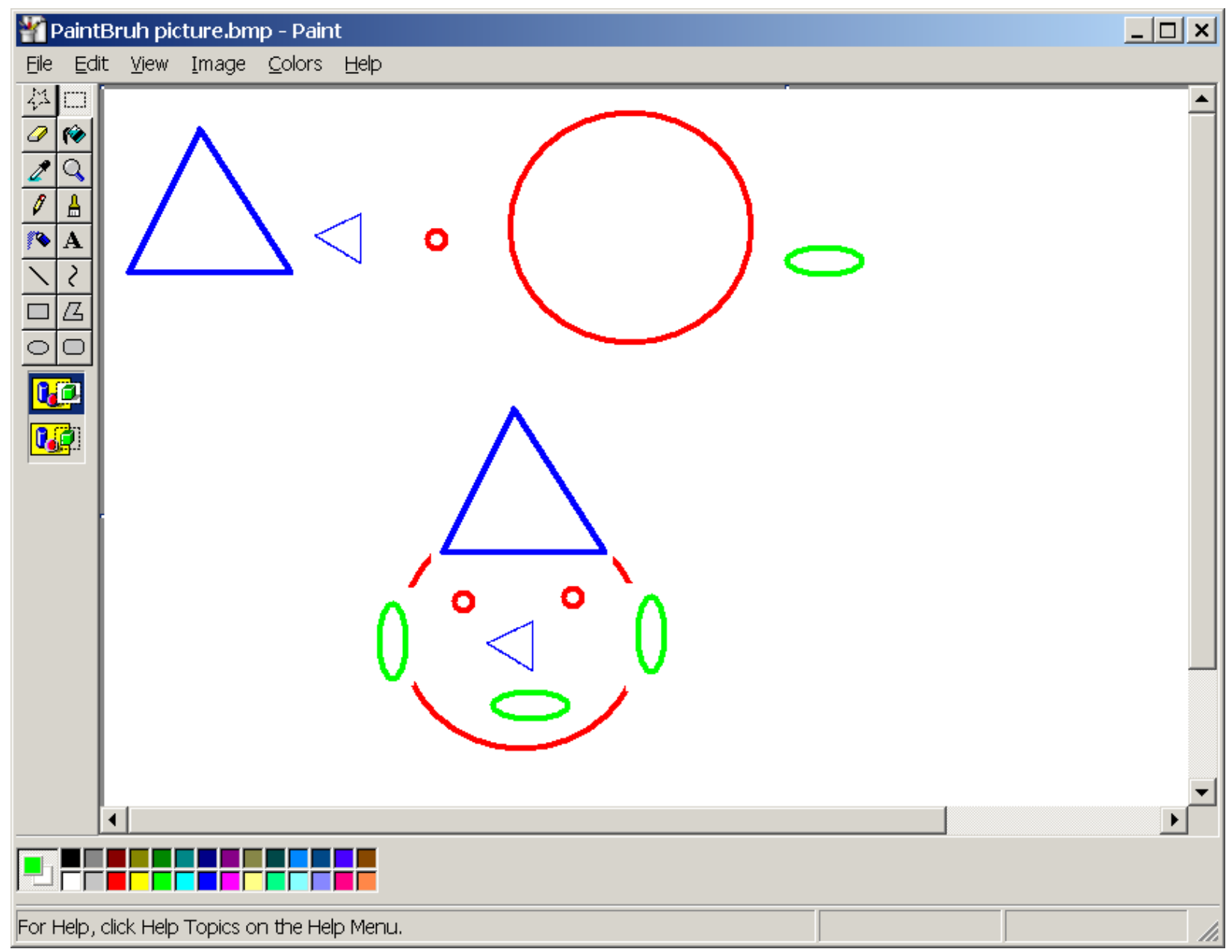

Picture 1. Eugene's suggestion of a learning activity based on Microsoft Paint for Saul: Make a face out of the given geometrical figures (the presented face is a possible solution).

Saul resonated with this advice, probably, thinking that a more attractive activity would keep children on his task of testing them. Eugene liked this activity for a different reason - he thought that the children might find this activity to be more playful, meaningful, and challenging than Saul's original test. Eugene's suggestion that Saul and the children make collages with Microsoft Paint was an occasion of socalled "boundary object" (Star \& Griesemer, 1989), meaning coordination of participants' (his and Saul's) different perceptions on and uses of the same object. Boundary objects make participants coordinate their diverse perceptions, functions, and roles in the activity without the participants having a shared goal or a shared vision of the activity. At the same time, Eugene and Saul set up a different type of examination. Eugene wanted Saul to compare the suggested learning activity with his experience testing children to determine which educational activities would feel better for him and for the children. At the same time, Saul wanted to compare Eugene's activity, understood by him as another "test," with Saul's original test - to see which test was better in his judgment. However, at the time, neither Eugene nor Saul would probably understand what "better" meant for them. What was "better" that emerged in Saul's experience and his reflection on this experience?

A day after making collages with children, Saul rushed to meet with Eugene and the TAs. He told Eugene that he was very excited because the children liked the activity, learned a lot from it, and, for the 


\section{Moving from collaboration to critical dialogue in action in education}

Eugene Matusov, Lucinda Pease-Alvarez

first time, enthusiastically asked him for guidance. Saul reported that kids often assigned themselves the task of drawing different pictures using the same geometrical figures that he had given them. He also reported that when he told the kids to draw the same type of picture, they would do so using different geometric figures. For the first time, he relaxed with the children at the center, had a good time with them, and felt good about himself as an educator. He also acknowledged that he was very surprised to find out that testing for students' "deficits" was not necessarily a prerequisite for sensitive guidance. He stated, "I almost did not think about guidance" - the activity itself and the children guided him how to guide them (cf. de Haan, 1999). The new relationship with the children and new guidance felt better for Saul than diagnosing the children's "educational deficits" and scaffolding to eliminate those "deficits."

Later in class, Saul shared this experience and told his classmates that he was confused about his role working with the children and unsure about the approach to teaching that he advocated. Some students, who, like Saul, advocated adult-run approaches to teaching and learning in the past, also revealed that they had problems engaging with children in the games and other activities. In contrast, students moving toward more children-run, collaborative, and dialogic approaches to teaching and learning provided alternative approaches and examples of how to engage more effectively with the children while playing games. As Saul and other class members struggled with their roles in working with children in the UCSCLinks Project, they found themselves in a community of people seeking child-run, collaborative, and dialogic types of guidance while also struggling with their own transmission-oriented educational backgrounds and with the diversity of the alternative, often poorly defined, approaches to guidance. At the end of his second UCSC-Links course, about three months after he attempted to test children, Saul wrote the following reflection about his learning experiences in the program.

Different opinions, different thoughts, different frustrations, all make up for a different learning experience. This change in structure can be difficult to adjust to at first. I recall my frustrations in the first quarter. We are so used to having teachers impose their structure on the student that we get frustrated when the responsibility is put into our hands. Eugene refuses to impose his structure on his students, and creates one which tries to be as free and open to student collaboration of course curriculum as possible (Saul, final paper, March 19, 1997).

Instead of dismissing or suppressing Saul's concerns about testing the children (i.e., that the children were trying to avoid him and his tests), Eugene took them seriously and tried to help him address them from his own perspective. He believed that the solution to Saul's problems lay in testing and examining his own pedagogical desires and commitments by trying to improve the quality of his interaction and relationship with children. His proposal was to make Saul's activity meaningful for the children because they owned the activity and participated in defining the goal of the activity (Matusov \& Marjanovic-Shane, 2019). Saul liked this proposal because it allowed him to test the children while securing their cooperation. When Saul was diagnosing the children's deficits using school-like tests, the goal of the activity was not open and negotiable for the children, which perhaps caused them to resist Saul's testing and avoid Saul. In trying to help Saul, Eugene wanted Saul (and similar students) to experience helpful and enjoyable engagements with the children in order to compare those engagements with Saul's experience testing the children. Eugene simply wanted Saul to enjoy working and being with the children (Matusov et al., 2016) rather than struggling to keep them on task and/or diagnose their educational deficits in order to fix them so that they fit some assumed "norm" (Matusov et al., 2016). However, it was up to Saul to judge his new experience and compare it with the old one. If upon reflection, Saul had concluded that giving children tests was better than making pictures and collages with them, Eugene would have accepted Saul's conclusion (cf. Bakhtin's notion of "the internally persuasive discourse," Bakhtin, 1991; Matusov \& von Duyke, 2010). 


\section{Moving from collaboration to critical dialogue in action in education}

Eugene Matusov, Lucinda Pease-Alvarez

In fact, some of Saul's classmates were convinced that testing was a more productive activity than collage making. Eugene didn't object to this conclusion as long as everybody continued to examine their pedagogical approaches and values through critical dialogue ${ }^{6}$.

Arguably, neither Eugene nor Saul clearly understood just what exactly a productive way would be to engage with and help the children. Nevertheless, they were both committed to defining and enacting such an approach. Eugene had struggled between drawing on a collaborative or dialogic approach to engaging with and supporting Saul. Saul struggled with how to engage with children productively by making them willing and successful testers. Thus, during their meetings, Eugene and Saul had created a zone of shared problem solving focused on searching for productive ways to engage with the children and one another. Although as the instructor, Eugene had different visions about how to approach the problem, he recognized that Saul's concerns were serious and real. The shared problem for Eugene and Saul was "a boundary object" (Star \& Griesemer, 1989).

In our view, Saul's transformations occurred because a dialogic process of goal-negotiation and value-testing in the project became open for all participants. As participants engaged in this process, they revealed their differing pedagogical goals and implicit values; then tried these goals out, and evaluated the desirability of their consequences on the children and Saul. This dialogic approach to providing guidance does not require a shared vision or a common shared educational philosophy or collaboration toward a common goal on the part of the instructor and the students (Fullan, 1993; Hargreaves, 1994). For a problem to be shared in critical dialogue, it does not need to be perceived in the same way by all the participants (Matusov, 1999). Rather, all participants should recognize and acknowledge a concern that generates the problem as genuine, real, important, and serious for others who have this concern, even though they may disagree with how to address it or what makes it a concern. In this case, Saul had been dissatisfied with his engagement with the children while testing and diagnosing their "deficits," while Eugene, who had seen difficulties in how Saul worked with the children, worried that Saul and the children might develop adversarial relations. The instructor was concerned about Saul's engagement with the children. However, Saul saw the problem in the UCSC-Links program as related to a "distractive" environment, while Eugene saw the problem as related to Saul's efforts to monopolize and control children's activity.

\section{Aspects of Critical Dialoguing in Action}

The events described above compelled us to reconsider our commitment to a sociocultural collaboration framework that conceives of participants as engaging in the process of jointly moving toward a common goal. According to this framework, collaboration involves resolving, reducing, neglecting, compromising, and, even at times, suppressing and manipulating participants' differences in the name of a particular desired collective outcome. This outcome can predate the collaboration itself - i.e., collaborationpoïesis, using an Aristotelian term (e.g., fixing a bike together). Alternatively, the collectively desired outcome can emerge in the collaboration - i.e., collaboration-praxis, using another Aristotelian term (e.g., solving an ill-defined problem together).

Recently, collaboration has become one of the primary virtues in social sciences. However, collaboration can be overreaching and abused. We concluded that there are two major problems with collaboration in general and specifically in education. The first problem is that not all instances of collaboration are honest. We define honest collaboration as occasions when: 1) the participants join in freely, instead of being coerced or manipulated, 2) the participants freely choose to neglect their

\footnotetext{
${ }^{6}$ Our educational pluralism guides us to accept students who may not be willing to engage in a critical dialogue as we do not believe in a forced critical dialogue. Genuine critical dialogue can be only voluntary.
} 


\title{
Moving from collaboration to critical dialogue in action in education
}

Eugene Matusov, Lucinda Pease-Alvarez

disagreements and/or to limit their attempts to explore issues in-depth, and 3) all participants desire and agree to achieve a collective outcome. Imposed, non-honest, collaborations include those occasions when some participants manipulate, exploit, coerce, oppress, or suppress other participants. Participants cannot be ordered to engage in honest collaboration.

The second problem with collaboration is that honest collaboration is not always possible and/or desirable. It is not always possible for the participants to honestly resolve, compromise, or limit their disagreements or desire the same collective outcomes. In line with this view, British philosopher Isaiah Berlin argued for a radical pluralism of values. According to Berlin, radical axiological pluralism

\begin{abstract}
... rejects the view that all conflicts of values can be finally resolved by synthesis and that all desirable goals may be reconciled. It recognises that human nature is such that it generates values which, though equally sacred, equally ultimate, exclude one another, without there being any possibility of establishing an objective hierarchical relation between them. Moral conduct therefore may involve making agonising choices, without the help of universal criteria, between incompatible but equally desirable values (Kelly, 1978, p. xv).
\end{abstract}

Moreover, in our view, there is no collectively desired outcome in education; - unless, of course, it becomes training, enforced by high-stake exams, tests, and a rigid, poïesis-like, practice (Matusov \& Marjanovic-Shane, 2012). If a general goal of education is to promote students' unique voices as they are involved in a range of practices of their choice; or to engage the students in critical examinations of their life, selves, world, society, and education (Matusov \& Marjanovic-Shane, 2019), the uniqueness of students' subjectivities is both the foundation and outcome of such education. Given this goal, there is no single subjectivity or voice that counts as an outcome but a variety of voices and subjectivities. In critical dialogue, the participants - the teachers and students - develop unique positions, unique worldviews, unique intonations, and unique desires that are brought into dialogues with each other and with other sources, outside of the immediacy of the classroom.

A framework that encompasses critical dialoguing in action more fully captures the ways undergraduates and instructor transformed their participation in the UCSC-Links project. These critical dialogues in action were venues of engagement during which we posited, drew upon, refined, questioned, and re-conceptualized our varying alternative perspectives, experiences, and goals, especially as they related to addressing issues or dilemmas in the afterschool program. As participants engaged in critical dialogue disagreed with one another, they questioned and deconstructed project goals and their roles, values, and interests.

So far, we have abstracted several aspects of this process. To illuminate the dialogic nature of these aspects, we juxtapose them with a one-sided, adult- and child-run, and collaborative alternative approaches to teaching and learning common in US educational practices.

1. Critical dialoguing expects, invites, and supports shared ownership for activities and education without assuming the common understanding, common goal, or agreement - All participants engage in decision-making and defining direction, values, and goals of the project, which do not need to be in agreement with each other. The curriculum, instruction, and learning trajectory are emergent and divergent here, rather than prescribed in advance. Guidance is driven by critical dialogue: by questioning, examining, testing, de- and re-constructing the participants' ideas, actions, goals, and values. In contrast, an adult-run approach expects the instructor to assume full responsibility for designing guidance and managing students' learning. Teachers who adhere to a child-run approach, 


\section{Moving from collaboration to critical dialogue in action in education}

Eugene Matusov, Lucinda Pease-Alvarez

do not provide any or only minimal guidance to the students in their decision-making and process of defining goals. Teachers who are attracted to a collaborative approach insist on having a common curriculum, common goal, and/or agreement-driven guidance.

2. Critical dialoguing develops, encourages, and supports public space for free discussions of hot issues, dilemmas, problems, and concerns of all project participants. All concerns are welcomed, respected, and recognized as genuine and serious. There is no expectation that participants will agree with one another. Sometimes, participants in UCSC Links did not even agree about whether something is a problem (e.g., not testing children had been a problem for Saul, but not for Eugene). An adult-run approach tends to silence those students who try to express opinions that contradict with, interfere with, or are considered wrong or irrelevant from the instructor's point of view. A child-run approach often involves leaving the students to their own devices and figuring out ways to articulate and deal with their own concerns and issues. A collaborative approach privileges agreement as it is grounded in the notion that participants must agree if they are to move forward and conceives of disagreements as temporary and as problems to be resolved and overcome (Latour, 1987).

3. Critical dialoguing fosters a safe learning environment so that participants' mistakes, explorations, and reflections about the consequences of their own actions are safe and valued resources for their own and other's learning. The differences among students and between the teacher and the students are the subject of critical dialoguing. An adult-run approach is likely to focus on ways to prevent students from making mistakes, to punish students for making mistakes, and/or to save the students from experiencing "negative consequences" for their actions. A child-run approach is less likely to provide support to the students for reflecting on their actions and/or not to interfere in order not to "spoil," "contaminate," or disrupt students' exploration and creativity. A collaborative approach makes learning unsafe when a student does not enter the consensus making process of deciding upon agreed-upon curricula, goals, approaches, and solutions to problems.

4. Critical dialoguing promotes a zone of shared legitimate problems, disagreements, and concerns among all participants. An adult-run approach often recognizes only those concerns that the instructor considers as legitimate by ignoring, overruling, diffusing students' concerns, and/or by making any emerging "hot" (i.e., concrete, close, personal, and urgent) issue "cold" (i.e., abstract, remote, anonymous, and general). A child-run approach tends to treat all problems and concerns as a matterof-taste or opinion -- individual preferences that cannot be judged or be the subject of dialogue with each other. A collaborative approach insists that in the long-run, everything should be common and agreeable.

5. Critical dialoguing generates alternative and diverse approaches, perspectives, values, and frameworks. An adult-run approach is more likely to limit students' focus to the instructor's approaches, perspectives, and frameworks. A child-run approach encourages the instructor to avoid sharing their own ideas, values, and preferences in order not to impose their views upon students' original creative thinking. A collaborative approach treats this diversity as temporary, to be resolved, and undesirable in the long-run.

Critical dialoguing in action promotes participants trying out their ideas in practice and then collectively evaluating them in a safe learning environment regardless of how disagreeable these ideas and evaluations are to some participants. Participants' reflections are embedded in an on-going critical dialogue (cf. Bakhtin, 1986; Bibler, 2009; Morson, 2004). Indeed, these dialogues may best be perceived of as inprocess and never-ending. An adult-run approach does not provide a safe learning environment for 


\section{Moving from collaboration to critical dialogue in action in education}

Eugene Matusov, Lucinda Pease-Alvarez

students to discuss their ideas. Instructors tend to shut down any disagreements that occur among students, thereby shutting down students' efforts to make meaning. They also often punish students who do not provide "correct" answers expected by the teachers. Instructors assuming a child-run approach may encourage students to examine their ideas in what appears to be a safe learning environment. But because instructors are committed to leaving students to their own devices, they are removed from students' deliberations and discussions and offer little if any feedback. Instructors committed to a collaborative approach may try to finalize dialogue by imposing an agreement either via silencing, use of the students' ignorance, or manipulation. For example, Socratic dialogues described by Plato involved Socrates' leading questions, hiding alternatives from his interlocutors, and providing false choices (Matusov, 2009). Collaborative instructors may avoid certain controversial issues because they don't envision students coming to a consensus over these issues.

There is another important difference between our critical dialoguing in action and the adult-run, child-run, and collaborative approaches. What defines each of these latter three approaches is their focus on establishing a monopolistic hold on educational institutions. Further, proponents of these approaches insist that only their approach is correct and worthy of being enacted in schools. In contrast, critical dialoguing in action is pluralistic in nature as it is grounded in principles that support and legitimize alternative perspectives. Paraphrasing the famous words on pluralism and freedom of speech often attributed to Voltaire, Matusov and Marjanovic-Shane insist, "I disapprove of your educational philosophy, but I will defend ... your right to use it in your... school" (Matusov \& Marjanovic-Shane, 2016, p. E3).

\section{Critical dialoguing as a transformation of participants: Our struggles}

Finally, we want to discuss two issues related to possible limitations of critical dialoguing as a way of developing and participating in our UC-Links project. The first issue involves a discussion of resources and institutional support necessary to sustain critical dialoguing. The second issue involves our concern that our participation in critical dialoguing privileges and, thus, imposes a worldview that may closely relate to our cultures and backgrounds and/or those of individuals in positions of power.

Projects grounded in a commitment to dialogic pedagogy need permanent and stable institutional support from states, universities, businesses, and communities in order to sustain themselves. Tenuous finances and meager institutional support have caused them to become further ensnared in traditional institutional hierarchies that have privileged adult-run pedagogical approaches. For example, in order to obtain funding, some UC Links projects agreed to focus their efforts on enhancing children's academic achievement as measured by standardized assessments. Consequently, these projects spent time developing those measures of achievement, assessing students using them, and involving students in adult-run activities that they thought would enhance their performance on those assessments.

Currently, funding many educational projects is overwhelmingly top-down and monopolistic in nature. This process focuses on discovering the "best practices" in education and then imposing them on educational institutions. Funding for projects is collected via taxes, centralized, and then redistributed by government agencies based on their (monopolistic) priorities. So-called best practices in education are those that government agencies tend to deem as worthy of funding. In contrast, we advocate an approach to funding that is based on and calls for educational pluralism (Matusov \& Marjanovic-Shane, 2016). This requires democratization and bottom-up redistribution of resources so that local projects decide on how they will use the funding.

Interestingly, this was what ultimately occurred when it came to funding the UCSC -Links project. In light of our perspective on the 5-D model that we describe above, we did not want or plan to use this 


\section{Moving from collaboration to critical dialogue in action in education}

Eugene Matusov, Lucinda Pease-Alvarez

model or any of its features. However, while UC Links leaders provided us as well as other campuses with resources on how to implement the 5-D model, they did not require campuses to use it. In our subsequent discussions with UC Links leaders, Michael Cole and Charles Underwood, they raised different perspectives about the value of using the 5-D model across all UC-Links projects. Michael Cole told us that he couldn't tell different campuses what to do in their specific programs. Yet he saw the value of using the $5-D$ model across campuses, which was evident when he told us that by allowing projects to freely implement the 5-D organizational model, users of that model could refine it in ways that responded to differences in the contexts in which the various programs were embedded. Michael Cole thought that implementing the Fifth Dimension model across sites was akin to "throwing it up into the wind and seeing where the seeds land ..."

In contrast, Charles Underwood had espoused much broader principles, defining the UC-links project as having the following four components: 1) an afterschool program, involving informal learning activities between undergraduates and kids, 2) an undergraduate course for the undergraduates participating in the afterschool program, 3) ongoing collaboration with the community, and 4) reflective research on the emerging practices. Charles Underwood told us that he favored a program where each project was free to generate their own approach to their work with children, undergraduates, and communities. As he told us, "I believe in building from the ground up and building from ... local knowledge and local structures ... and look[ing] at ways people build things up in their culture and their social world." The differences and disagreements about the project's vision did not preclude the participants from supporting each other's efforts, including the provision of funding.

As we further reflect on our own frames of reference and how they have contributed to the way we participated in the UC-Links project, it occurs to us that our notion of critical dialoguing may privilege and, thus, impose our own world view shaped by our cultures, societal positioning, and experiences (Matusov, 2018; Matusov \& Lemke, 2015). To some degree, we feel that this is true, and we are ambivalent about that. On the one hand, from our vantage point, our backgrounds and understandings are building materials for our practices. Hence, they both delineate and support our practices. Our backgrounds situate us in the universe of history, give us home (i.e., anchor and solace), and compel our passions. On the other hand, our biases, particularly when endorsed by institutions and status quos power hierarchies, might compel us and others to endorse specific pedagogies and cultural practices. We think there is an inherent tension between participants' biases and the pedagogical pluralism necessary for a genuine dialogue.

This is particularly apparent in our struggles to accommodate or transcend our own adult-run and collaborative teaching backgrounds and institutional arrangements so that we can fully embrace a pluralistic dialogic philosophy of teaching and learning (Matusov \& Marjanovic-Shane, 2016). Having experienced traditional adult-run and collaborative schooling approaches first as students, and then as teachers, we feel that we probably will continue to utilize these pedagogical approaches. Indeed, as autobiographically adultrun and collaborative instructors, often, our immediate response to issues or challenges that emerge in our classes is to draw upon our arsenal of adult-run and collaborative practices. Further, the institutions we work in are organized in such a way as to encourage and almost demand that we engage in adult-run, autocratic, educational practices.

Finally, there are occasions when the power dynamics that come into play during critical dialoguing can complicate our work. For example, we have experienced occasions when some undergraduates who identify as LGBTQ have felt strongly that they should be able to reference their sexual orientation and/or gender identity in their work with children while others have disagreed. Consequently, on occasions when LGBTQ students have done so, for example, in response to children's questions, they have been criticized 


\section{Moving from collaboration to critical dialogue in action in education}

Eugene Matusov, Lucinda Pease-Alvarez

by others. For some of these students, these critiques have been painful as they have interpreted them to be expressions of disdain or hate. On these and other occasions, instructors who have struggled to support dialogue when undergraduates appear angry or upset find it "easier" to insist on a specific course of action regardless of context (e.g., a rule banning any reference to sexual orientation or gender identity) or to seek consensus.

In realizing and accepting these tendencies, we are learning to confront them directly and not to be paralyzed by, deny or rationalize our adult-run and collaborative pedagogical actions (Matusov, MarjanovicShane, \& Gradovski, 2019). This realization helps us to avoid unreasonable expectations from others and ourselves. Thus, discovering and using elements of traditional adult-run and collaborative philosophies in our practice is not evidence of our failure, hypocrisy, or surrender but something that we expect from ourselves and are ready to confront. In this process, we are working toward transcending known and unknown limitations of our own sociocultural, historical, and personal upbringings.

\section{References}

Argyris, C., \& Schön, D. A. (1978). Organizational learning: A theory of action perspective. Reading, MA: AddisonWesley Pub. Co.

Bakhtin, M. M. (1986). Speech genres and other late essays. Austin, TX: University of Texas Press.

Bakhtin, M. M. (1991). The dialogic imagination: Four essays by M. M. Bakhtin (C. Emerson \& M. Holquist, Trans.). Austin, TX: University of Texas Press.

Bakhtin, M. M. (1999). Problems of Dostoevsky's poetics. Minneapolis: University of Minnesota Press.

Bibler, V. S. (2009). The foundations of the School of the Dialogue of Cultures Program. Journal of Russian \& East European Psychology, 47(1), 34-60.

Bigelow, W. (1996). On the road to cultural bias: A critique of "The Oregon Trail" CD-ROM. In E. Lee, D. Menkart, \& M. Okazawa-Rey (Eds.), Beyond heroes and holidays: A practical guide to K-12 anti-racist, multicultural education and staff development (pp. 355-363). Washington, DC: Network of Educators on the Americas.

Cole, M. (2006). The fifth dimension: An after-school program built on diversity. New York: Russell Sage.

de Haan, M. (1999). Learning as cultural practice: How children learn in a Mexican Mazahua community. Amsterdam: Thela Thesis.

Dorr-Bremme, D. W., \& McDougall, B. (1999, April). Constructing contexts for learning: Relationships among communities of practice. Paper presented at the American Educational Research Association, Montreal, Canada.

Engeström, Y. (1990). Learning, working, and imagining. Helsinki, Finland: Orienta-Konsultit Oy.

Fullan, M. (1993). Change forces: Probing the depth of educational reform. London; New York: Falmer Press.

Hargreaves, A. (1994). Changing teachers, changing times: Teachers' work and culture in the postmodern age. London: Cassell.

Kelly, A. (1978). Introduction: A complex vision. In I. Berlin, H. Hardy, \& A. Kelly (Eds.), Russian thinkers (pp. xiii-xxiv). London: Hogarth Press.

Latour, B. (1987). Science in action: How to follow scientists and engineers through society. Cambridge, MA: Harvard University Press.

Lave, J. (1992, April). Learning as participation in communities of practice. Presented at the meeting of the American Educational Research Association. http://www.udel.edu/educ/whitson/897s05/files/Lave92.htm

Lave, J., \& Wenger, E. (1991). Situated learning: Legitimate peripheral participation. Cambridge, UK: Cambridge University Press.

Marjanovic-Shane, A. (2016). "Spoilsport" in drama education vs. dialogic pedagogy. Dialogic Pedagogy: An International Online Journal, 4, A45-A80. http://dpi.pitt.edu/ojs/index.php/dpj1/article/view/151/113 doi:10.5195/dpj.2016.151

Marjanovic-Shane, A., Meacham, S., Choi, H. J., Lopez, S., \& Matusov, E. (2019). Idea-dying in critical ontological democratic dialogue in classrooms. Learning, Culture and Social Interaction, 20, 68-79. doi:10.1016/j.Icsi.2017.10.001 


\section{Moving from collaboration to critical dialogue in action in education}

Eugene Matusov, Lucinda Pease-Alvarez

Marsick, V., \& Watkins, K. (1990). Informal and incidental workplace learning. New York: Routledge.

Matusov, E. (1998). When solo activity is not privileged: Participation and internalization models of development. Human Development, 41(5-6), 326-349.

Matusov, E. (1999). How Does a Community of Learners Maintain Itself? Ecology of an Innovative School. Anthropology \& Education Quarterly, 30(2), 161-186.

Matusov, E. (2009). Journey into dialogic pedagogy. Hauppauge, NY: Nova Science Publishers.

Matusov, E. (2015a). Comprehension: A dialogic authorial approach. Culture \& Psychology, 21(3), 392-416. doi:10.1177/1354067X15601197

Matusov, E. (2015b). Legitimacy of non-negotiable imposition in diverse approaches to education. Dialogic Pedagogy: An International Online Journal, 3, A174-A211. http://dpj.pitt.edu/ojs/index.php/dpj1/article/view/110/105

Matusov, E. (2018). Chronotopic analysis of values in critical ontological dialogic pedagogy. In A. U. Branco \& M. C. Lopes-de-Oliveira (Eds.), Alterity, Values and Socialization: Human Development within Educational Contexts (pp. 1-29). Cham, Switzerland: Springer.

Matusov, E., Bell, N., \& Rogoff, B. (2002). Schooling as cultural process: Shared thinking and guidance by children from schools differing in collaborative practices. In R. Kail \& H. W. Reese (Eds.), Advances in Child Development and Behavior (Vol. 29, pp. 129-160). New York: New York: Academic Press.

Matusov, E., \& Marjanovic-Shane, A. (2012). Diverse Approaches to Education: Alienated Learning, Closed and Open Participatory Socialization, and Critical Dialogue. Human Development, 55(3), 159-166. doi:10.1159/000339594

Matusov, E., \& Marjanovic-Shane, A. (2015). Typology of critical dialogue and power relations in Democratic Dialogic Education. In K. Jezierska \& L. Koczanowicz (Eds.), Democracy in dialogue, dialogue in democracy (pp. 211229). Farnham, UK: Ashgate Publishing, Ltd.

Matusov, E., \& Marjanovic-Shane, A. (2016). The State's Educational Neutrality: Radical proposal for educational pluralism (Editorial). Dialogic Pedagogy: An International Online Journal, 4, E1-E26. http://dpj.pitt.edu/ojs/index.php/dpi1/article/view/170/114 doi:10.5195/dpj.2016.170

Matusov, E., \& Marjanovic-Shane, A. (2019). Intrinsic education and its discontents. In L. Tateo (Ed.), Educational dilemmas: A cultural psychological perspective (pp. 21-40). New York: Routledge.

Matusov, E., \& Smith, M. P. (2011). Ecological model of inter-institutional sustainability of after-school program: The La Red Mágica community-university partnership in Delaware. Outlines: Critical Social Studies, 5(1), 19-45.

Matusov, E., Smith, M. P., Soslau, E., Marjanovic-Shane, A., \& von Duyke, K. (2016). Dialogic education from and for authorial agency. Dialogic Pedagogy: An International Online Journal, 4, A162-A197. http://dpj.pitt.edu/ojs/index.php/dpj1/article/view/172/130 doi:10.5195/dpj.2016.172

Matusov, E., \& von Duyke, K. (2010). Bakhtin's notion of the Internally Persuasive Discourse in education: Internal to what? (A case of discussion of issues of foul language in teacher education). In K. Junefelt \& P. Nordin (Eds.), Proceedings from the Second International Interdisciplinary Conference on perspectives and limits of dialogism in Mikhail Bakhtin Stockholm University, Sweden June 3-5, 2009 (pp. 174-199). Stockholm: Stockholm University.

Morson, G. S. (2004). The process of ideological becoming. In A. F. Ball \& S. W. Freedman (Eds.), Bakhtinian perspectives on language, literacy, and learning (pp. 317-331). Cambridge, UK; New York: Cambridge University Press.

Nicolopoulou, A., \& Cole, M. (1993). Generation and transmission of shared knowledge in the culture of collaborative learning: The Fifth Dimension, its play-world, and its institutional contexts. In E. A. Forman, N. Minick, \& C. A. Stone (Eds.), Contexts of learning: Sociocultural dynamics in children's development (pp. 283-314). New York: Oxford University Press.

Nocon, H. D. (2005). Productive resistance: Lessons from after-school and engaged non-compliance. American Journal of Education, 111(2), 191-210.

Rogoff, B. (1990). Apprenticeship in thinking: Cognitive development in social context. New York: Oxford University Press.

Rogoff, B. (2014). Learning by observing and pitching in to family and community endeavors: An orientation. Human Development, 57(2-3), 69-81.

Rogoff, B. (2016). Culture and participation: A paradigm shift. Current Opinion in Psychology, 8, 182-189.

Dialogic Pedagogy: An International Online Journal | https://dpj.pitt.edu

DOI: 10.5195/dpj.2020.292 | Vol. 8 (2020) 


\section{Moving from collaboration to critical dialogue in action in education \\ Eugene Matusov, Lucinda Pease-Alvarez}

Rogoff, B., Matusov, E., \& White, C. (1996). Models of teaching and learning: Participation in a community of learners. In D. R. Olson \& N. Torrance (Eds.), The handbook of education and human development: New models of learning, teaching and schooling (pp. 388-414). Malden, MA, US: Blackwell Publishers Inc.

Rogoff, B., Mejia-Arauz, R., \& Correa-Chávez, M. (2015). A cultural paradigm—Learning by observing and pitching in. In Advances in child development and behavior (Vol. 49, pp. 1-22): Elsevier.

Star, S. L., \& Griesemer, J. R. (1989). Institutional ecology, "translations" and boundary objects: Amateurs and professionals in Berkeley's museum of vertebrate zoology, 1907-39. Social Studies of Science, 19(3), 387420.

Wood, D., Bruner, J. S., \& Ross, G. (1976). The role of tutoring in problem solving. Journal of Child Psychology and Psychiatry, 17, 89-100.

\section{(cc) BY}

New articles in this journal are licensed under a Creative Commons Attribution 4.0 United States License.

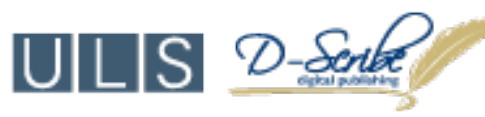

This journal is published by the University Library System, University of Pittsburgh as part of its D-Scribe Digital Publishing Program and is cosponsored by the University of Pittsburgh Press. 